\title{
Effect of severe plastic deformation and subsequent silicon spheroidizing treatment on the microstructure and mechanical properties of an Al-Si-Mg alloy
}

\author{
N. Haghdadi ${ }^{1, *}$, A. Zarei-Hanzaki ${ }^{2}$, M. Kawasaki ${ }^{3,4}$, A.B. Phillion ${ }^{5}$, P.D. Hodgson ${ }^{1}$ \\ ${ }^{1}$ Institute for Frontier Materials, Deakin University, Geelong, Victoria 3216, Australia \\ ${ }^{2}$ School of Metallurgy and Materials Engineering, College of Engineering, University of Tehran, Tehran, \\ Iran \\ ${ }^{3}$ Division of Materials Science and Engineering, College of Engineering, Hanyang University, Seoul 133- \\ 791, South Korea \\ ${ }^{4}$ Departments of Aerospace and Mechanical Engineering and Materials Science, University of Southern \\ California, CA 90089-1453, USA \\ ${ }^{5}$ Department of Materials Science and Engineering, McMaster University, Hamilton, ONL8S 4L7, Canada \\ *Corresponding author, E-mail: nhaghdad@deakin.edu.au; Tel: +61352479383
}

\begin{abstract}
The present study investigated the synergetic effects of severe plastic deformation (SPD) and subsequent heat treatment on the microstructure and mechanical characteristics of a hypoeutectic $\mathrm{Al}-7 \mathrm{Si}-0.4 \mathrm{Mg}$ (A356) alloy. It was shown that severe deformation by accumulative back extrusion (ABE) at $300{ }^{\circ} \mathrm{C}$ substantially refined the $\alpha$-Al primary phase and Si particles, but did not homogeneously redistribute the Si particles in the $\alpha-\mathrm{Al}$ matrix. $\mathrm{ABE}$ processing also improved the strength but did not enhance the ductility. In order to make a compromise between strength and ductility, a subsequent heat treatment at $540{ }^{\circ} \mathrm{C}$ was carried out in the current work. It was shown that severe plastic deformation of the material can substantially accelerate the silicon spheroidization. Heat treatment at $540{ }^{\circ} \mathrm{C}$ increased the ductility of the material from $\sim 8 \%$ (in the deformed condition) to $\sim 15 \%$. The enhancement of ductility was discussed with emphasis on the microstructure evolution involving restoration of the matrix during high temperatures heat treatment, spheroidization of the Si particles, and redistribution of the Si particles within the $\alpha-\mathrm{Al}$ matrix.
\end{abstract}


Keywords: Aluminum alloys; severe plastic deformation; silicon spheroidizing; mechanical properties

\section{INTRODUCTION}

Recent interests in eco-friendly, light-weight, and recyclable materials have spotlighted aluminum alloys as promising substitutes for conventional ferrous parts [1]. Specifically, owing to their excellent fluidity during casting and high corrosion resistance, aluminum-silicon (Al-Si) alloys are attractive materials to be exploited in such fields as automotive and aerospace industries. Hypoeutectic A356 aluminum alloy is one of the most commonly-used foundry alloys within the Al-Si system, for applications ranging from wheels to support brackets within automobiles [2]. Si particles with irregular length and embedded in the coarse aluminum casting matrix, however, provide only moderate strength enhancement and very limited ductility, which consequently impedes the application of this alloy.

Modifications in the shape and size of Si particles together with refinement in the matrix structure are key strategies to improve the mechanical performance of this alloy [3]. Microstructural refinement in A356 alloy can be achieved through a number of routes and classified into two main categories; the ones done during casting of the material and the ones which are done after the casting process. The first category consists of methods such as chemical modification through the addition of such elements as sodium, antimony, and strontium to the melt [4], employing high cooling rates during casting [5], and using thermal treatment in which mixing of low and high temperature melts results in a fine silicon structure [6]. The second category consists of methods to modify the as-cast microstructure including heat treatment of the A356 alloy resulting in the dissolution of precipitates and silicon spheroidization [7], thermomechanical processing (i.e., concurrent application of heat and deformation) [8], and severe plastic deformation [9-16]. In all cases the main goal is to improve the mechanical properties of the A356 aluminum alloy. 
In practice, soaking the material at $540{ }^{\circ} \mathrm{C}$ for a particular duration to homogenize the structure and spheroidize the Si particles is the most straightforward procedure to modify the microstructure of this alloy. Heat treatment of the alloy at $540{ }^{\circ} \mathrm{C}$ for several hours is, however, time-consuming and costly. In this regard, Ogris et al. [17] has reported a novel approach in which chemical modification has been coupled to silicon spheroidization through high temperature heat treatment. It was shown that spheroidization would be highly accelerated and completed within few minutes when silicon is modified during casting using strontium. This is because modification induces a high density of crystal defects such as terminations, kinks and striations, which are potential points for fragmentation and further spheroidization of Si particles during subsequent heat treatment.

During the last decade, application of severe plastic deformation (SPD) to refine microstructure and trigger phase transformation has been well documented for various metals and alloys $[18,19]$. In the case of aluminum-silicon alloys, various researchers have applied several SPD methods to enhance mechanical performance of the alloy through microstructural refinement. In one study, Gutierrez-Urrutia et al. [20] comparatively studied the effect of equalchannel angular pressing (ECAP) on the microstructure evolution and mechanical properties of $\mathrm{Al}-0.5 \% \mathrm{Si}$ and $\mathrm{Al}-7 \% \mathrm{Si}$, and reported that a significantly higher dislocation density and much finer grains was achieved in the alloy with $7 \% \mathrm{Si}$. In another study by the same authors [10] on ECAP processed Al-7\% Si alloy, while no significant differences in tensile strength were found for materials processed through different routes (i.e., $A, B_{A}, B_{c}, C$ [21]), significant differences were observed in ductility. This was attributed to differences in geometric redistribution of the eutectic constituent obtained under different processing routes. Mungole et al. [22] studied the effect of strain and temperature on the microstructure and hardness of high pressure torsion (HPT)-processed Al-7\% Si alloy. They reported smaller grain sizes and more rapid grain refinement with homogeneous distribution of small Si particulates for the 
samples processed at the low temperature. Haghdadi et al. [23] observed significant change in microstructure as a result accumulative back extrusion (ABE) processing of A356 at two different temperatures. Substantial enhancement in mechanical strength was also reported for an A356 alloy processed with different SPD methods such as friction stir processing (FSP) [24] and accumulative roll bonding (ARB) [25].

Although a high attention has been paid to improving the mechanical performance of A356 via SPD, there are few reports studying the effect of SPD processing on the subsequent silicon spheroidization response of the material. Additional heat treatment after SPD processing is anticipated to improve ductility in the material, which is generally lost during SPD due to the inverse relationship between strength and ductility upon grain refinement [26]. In this study, the synergistic effects of SPD processing together with subsequent heat treatment have been investigated in A356 alloys in order to improve ductility while maintaining elevated strength. First, ABE processing [27] was employed to provide the severe strain, and heat treatment was applied at $540{ }^{\circ} \mathrm{C}$ for different durations to spheroidize silicon. Then, the evolution of microstructure and mechanical properties of the experimental alloy were studied in a comprehensive manner using back-scattered scanning electron microscopy and electron back-scattered diffraction analysis together with miniaturized tensile testing.

\section{EXPERIMENTAL PROCEDURE}

The material used in this study was a thixo-cast A356 aluminum alloy with the chemical composition (wt. \%) of Al-7.5Si-0.4Mg-0.15Cu-0.03Mn-0.02Ti. Cylindrical specimens of 18 $\mathrm{mm}$ in diameter and $8 \mathrm{~mm}$ in height were machined from the thixo-cast ingot.

Processing through $\mathrm{ABE}$ was applied for one pass on the alloy at the temperature of $300^{\circ} \mathrm{C}$ using a $300 \mathrm{kN}$ servo-electric universal testing machine under a ram speed of $5 \mathrm{~mm} / \mathrm{min}$. The principles of $\mathrm{ABE}$ processing and the details of the facility was explained elsewhere [28]. 
In brief, as is shown in Fig. 1 [29], one complete pass of ABE processing consists of initial back extrusion and subsequent two-dimensional constrained back-compression. In ABE, after locating the cylinder-shape specimen in the die (Fig. 1a), the workpiece is back-extruded into the gap between the inner punch and the die (Fig. 1b). Afterwards, the back extruded part is compressed back to the initial dimension using the outer punch (i.e., hallow ram) completing one ABE cycle (Fig. 1c and d). It should be noted that the inner punch is carefully designed so that it tightly slides during the different steps. Graphite spraying was applied to reduce the friction between the workpiece and the die surfaces. The specimen was held isothermally at $300^{\circ} \mathrm{C}$ for 5 min prior to $\mathrm{ABE}$ to achieve thermal equilibration throughout the specimen. Immediately after the ABE process, the deformed specimen was quenched in warm water with a temperature of $\sim 60^{\circ} \mathrm{C}$. After $\mathrm{ABE}$ processing, some of the processed work-pieces were subjected to heat treatment at $540^{\circ} \mathrm{C}$ for various durations of $2,4,8$, and $30 \mathrm{~min}$. The heat treated specimens were immediately quenched also in warm water at $\sim 60^{\circ} \mathrm{C}$.

To examine the hardness of the ABE/heat treated samples, the Vickers microhardness measurements were performed on polished cross sections. Five separate Vickers hardness indentations were conducted under a load of $10 \mathrm{~kg}$ for each sample at the middle of the vertical cross-sections. Care was taken to make sure that the indentations were adequately spaced so that the strain hardened areas around each indentation did not influence one another. Finally, tensile testing was performed to measure the mechanical properties of the material. This was carried out using a tensile testing facility equipped with a small-scale sample holder using specimens with gage dimensions of $10 \mathrm{~mm}$ length, $1.5 \mathrm{~mm}$ width and $0.7 \mathrm{~mm}$ thickness.

For metallography, the specimens were sectioned parallel to the extrusion axis and the cut surface was ground, polished and etched by Keller's reagent. A scanning electron microscope (SEM, CamScan, MV2300) equipped with an image analyzer was employed for microstructure examination. The fracture surface was examined for the samples after tensile 
testing using SEM. The subsurface region of the fracture surface was also examined using optical microscopy. The EBSD analysis was carried out using a Zeiss LEO 1530 FEG SEM equipped with a HKL attachment. The operation voltage and step size were $10 \mathrm{kV}$ and $100 \mathrm{~nm}$, respectively. The center of the vertical cross-section of the samples was analyzed by EBSD. Data post-processing was performed using the AZtec ${ }^{\mathrm{TM}}$ software.

\section{3- RESULTS AND DISCUSSION}

\subsection{Initial microstructure}

The microstructure of the experimental alloy in the thixo-cast condition consists of Sirich eutectic regions (dark color) embedded in a solid solution aluminum matrix (bright color) as shown in Fig. 2 (a). Specifically, the experimental A356 alloy contains globular $\alpha$-Al phase surrounded by continuous eutectic region. As seen in Fig. 2(a), the matrix contains the globular $\alpha$-Al grains with a diameter of 20 to $100 \mu \mathrm{m}$. Figure 2(b) shows a magnified view of the eutectic region. The Si fibers exhibit a mean diameter of $\sim 0.5 \mu \mathrm{m}$ in cross section and a length in the range of $\sim 1$ to $\sim 5 \mu \mathrm{m}$.

\subsection{Microstructural evolution after ABE}

Fig. 3(a) shows the EBSD micrograph of the material after ABE for one complete pass

at $300{ }^{\circ} \mathrm{C}$. The material can be seen to conserve its initial microstructure in terms of globule size and morphology as well as the position of the eutectic region; i.e., mixing of the eutectic and matrix regions did not occur. A similar response to severe plastic deformation has been previously observed for $\mathrm{Al}-\mathrm{Si}$ alloys after routes $\mathrm{C}$ or $\mathrm{B}_{c}$ of ECAP [9]. This, however, contradicts with the homogenous distribution of Si particles within the matrix after HPT and FSP of the same alloy [14, 24].

EBSD analysis revealed that the deformed specimen shows a sub-grain structure (grey lines inside the globules) as seen in Fig. 3a. This is in line with the previous studies on the 
severe deformation of aluminum alloys [23,28-31]. Due to high stacking fault energy of aluminum alloys, the micro-mechanisms for the strain accommodation in the primary alpha aluminum globules are based on dislocation-cell formation mechanisms. Most of the boundaries inside the globules were of type low-angle, i.e. less than $15^{\circ}$ misorientation angle. Thus, the active grain refinement mechanism during ABE processing of A356 Al alloy is continuous dynamic recrystallization. This is confirmed by the misorientation angle distribution of the boundaries in this alloy after $\mathrm{ABE}$ showing a peak at low angle grain boundaries with a gradual reduction in population with increasing misorientation angle (Fig. 3c). During ABE, dislocation boundaries are generated; the density of which increase with increasing strain. The material then tends to form cells because it is energetically easier for a grain to deform if it splits into cell blocks that deform through fewer than the five independent slip systems required for constrained deformation [32]. Cells surrounded by dislocations will gradually turn to more equilibrium (sub)grain boundaries through increasing their misorientation.

The distribution of strain across the microstructure of ABE-processed specimen is illustrated through kernel average maps (KAM) (Fig. 3 b,d). Most of the regions inside the alpha grains showed a local lattice rotation of less than $1^{\circ}$. The highest lattice rotation (sometimes as high as $2.5^{\circ}$ ) was, however, observed for the eutectic region. This shows that a considerable strain gradient is mostly concentrated within the eutectic regions. This is due to the intense strain incompatibility at the $\mathrm{Al} / \mathrm{Si}$ interfaces. As a result, a deformation zone with a high dislocation density and large lattice misorientation could be formed near the brittle large Si particles. Such high density of geometrically necessary dislocations would also provide a strong driving force for grain refinement through substantially accelerating the dynamic recrystallization phenomenon (i.e. particle stimulated nucleation phenomenon). 
By comparing Figure $2 b$ and Figure 4, it can be seen that the size of the Si particles was refined as a result of severe plastic deformation, changing from about $2.8 \mu \mathrm{m}$ in diameter in the thixo-cast condition to $0.7 \mu \mathrm{m}$ after ABE. Refinement of Si particles occurs due to both thermal and mechanical fragmentation. It has been proposed that during holding of the A356 alloy at high temperatures, $\mathrm{Si}$ particles go through fragmentation, spheroidization and ultimately coarsening [7]. Thermal disintegration starts from crystal defects such as terminations, kinks and striations (i.e., Rayleigh's criteria) [7]. Furthermore, significant strain incompatibility occurs during $\mathrm{ABE}$ at the $\mathrm{Si}$ particle / $\mathrm{Al}$ matrix interface. This is because $\mathrm{Al}$ and Si have different elastic constants and deformation behavior. This ultimately leads to cracking and fragmentation of the Si particles. As the ABE testing temperature is not very high, mechanical fragmentation seems to play the main role in the refinement of Si particles.

\subsection{Microstructural evolution after post-ABE heat treatment}

To study the effect of $\mathrm{ABE}$ processing on the subsequent heat treatment of A356 alloy, the samples processed by a complete pass of $\mathrm{ABE}$ were soaked at $540^{\circ} \mathrm{C}$ for different durations. It was observed that the $\mathrm{Si}$ particles which have been refined through $\mathrm{ABE}$ tended to spheroidize and coarsen with time as exhibited in Fig. 5. A decrease in both interfacial energy and elastic strain energy are the main triggering parameters for spheroidization of Si particles [7]. Si atoms tend to leave sharp edges towards round ones due to capillary forces, which ends in spheroidization. The size and roundness of Si particles after different heat treatments is also included in Fig. 5. The highest roundness was achieved after two minutes. Afterwards the Si particles started to grow. As the growth of Si particles is anisotropic [8], they will lose their spherical shape during coarsening. The main driving force for coarsening of Si particles is a reduction in surface energy since a small number of large precipitates contains less interface as compared to a large number of small precipitates (i.e., Gibbs-Thomson effect) [33]. Coarsening may be due to the supply of Si atoms diffusing out of the cores of dendrites, and/or 
through the Ostwald ripening mechanism in which the larger particles grow at the expense of the smaller ones. There is a reasonable linear relationship between Si mean diameters with the 3rd root of time during heat treatment (Fig. 5f). This shows that Si particles coarsen through Ostwald ripening.

Compared to the previous works on heat treatment of A356, it is interesting to note that when the material is severely deformed through $\mathrm{ABE}, \mathrm{Si}$ is spheroidized in a much shorter time (i.e. 2 min) [7]. This finding, which has considerable practical implications, is attributed to the microstructural evolutions induced by $\mathrm{ABE}$. We hypothesize that the increase in the kinetics of spheroidization is a result of the high strain achieved during $\mathrm{ABE}$, which accelerates strain induced diffusion mainly through dislocation pipe diffusion of $\mathrm{Si}$ within $\mathrm{Al}$ matrix. Moreover, $\mathrm{ABE}$ induces a high density of interfacial instabilities in the Si particles, which are necessary for fragmentation and spheroidization of $\mathrm{Si}$ particles. The important role of morphological faults on the kinetics of silicon spheroidization has been previously reported by Haghdadi et al [8], Apelian et al [34], and Lados et al [35].

The general microstructure obtained after heat treatment at $540{ }^{\circ} \mathrm{C}$ for $2 \min$ is displayed in Fig. 6a. It is observed that the alpha globules coarsened during heat treatment. It is also observed that the $\mathrm{Si}$ particles are not anymore in the intergranular regions but have moved to interior of the grains. Moreover, as a result of recovery and annihilation of dislocations, a large number of low angle gain boundaries, previously observed in the as- $\mathrm{ABE}$ processed conditions, have disappeared. This is reflected in the mis-orientation angle distribution of the boundaries which shows a shift towards higher angle boundaries when compared with the ABE-processed condition (Fig. 6c). The annihilation of dislocations also substantially reduced the local lattice rotation across the microstructure (Fig. 6b,d). It was observed that most of the regions showed a local rotation of less than $0.5^{\circ}$. This is much less than what was observed for the ABE-processed sample. Moreover, as the Si particles were 
dissolved and/or moved towards inside the alpha grains, the intergranular stress concentration was not observed anymore. In fact, in this case, stress concentrations were found within the alpha grains adjacent to the Si particles.

\subsection{Hardness evolution}

Figure 7 compares the evolution of hardness with heat treatment time at $540^{\circ} \mathrm{C}$ between the ABE-processed specimen and the initial thixo-cast material. For the thixo-cast sample, a peak in hardness is observed after 8 min followed by a drop, showing that Si particles achieve their maximum spehricity within that time. Afterwards, coarsening of Si particles would destroy the mechanical properties. This is in line with the previous studies on SST of A356 alloy [36]. For the ABE-processed sample, however, it is seen that the material softens in the earlier stages of heat treatment. This is mainly due to recovery of the highly strained microstructure. The rate of softening then decreases showing the spheroidization of Si particles. Once the peak roundness is achieved, material again softens at a higher rate due to the $\mathrm{Si}$ particles becoming coarser.

\subsection{Tensile behavior}

The yield and ultimate tensile stress together with elongation for four different conditions of thixo-cast (initial), ABE-processed, ABE-processed followed by 2 min heat treatment (spheroidized), and ABE-processed followed by 30 min heat treatment (coarsened) have been given in Table 1. As is seen, ABE dramatically increases the yield and tensile strength. Ductility is however destroyed and it was reduced from $9.1 \%$ in the initial condition to about $8.0 \%$ in the $\mathrm{ABE}$-processed state. Heat treatment at $540^{\circ} \mathrm{C}$ for 2 min resulted in a loss in strength (UTS dropped by $28 \%$ while YS decreased by $2 \%$ ), and an enhancement in the ductility (an increase of $\sim 91 \%$ ). Prolonged heat treatment (i.e., 30 min) however, decreased 
yield and ultimate strength while elongation slightly increased (from $15.3 \%$ to $17 \%$ ). This implies that a compromise between strength and ductility for A356 Al alloy would be achieved by coupling $\mathrm{ABE}$ and $2-\mathrm{min}$ heat treatment at $540^{\circ} \mathrm{C}$.

The increase in the strength of the material after $\mathrm{ABE}$ is attributed to reduction in the grain and $\mathrm{Si}$ particles size together with a substantial increase in the dislocation density. As was seen in Fig. 3a low angle grain boundaries are formed during ABE which can strengthen the material through Hall-Petch mechanism. High dislocation density induced by ABE (shown by KAM map in Fig. 3c) also hardens the material through the Bailey-Hirsch mechanism [3]. Finally, it has been found that Si refinement increases the required critical stress for developing a crack needed for fracture of a particle which in turn improves the tensile strength of the A356 Al alloy [37]. During heat treatment at $540^{\circ} \mathrm{C}$, subgrains annihilate, dislocation density deceases, and Si particles coarsen.

The experimental alloy showed a decrease in elongation after ABE processing. This could be due to inhomogeneous distribution of strain across the ABE-processed specimen, which, in turn, leads to flow localization. However, ductility significantly increased after heat treatment for 2 min at $540^{\circ} \mathrm{C}$. This can be explained by considering a number of factors. First, dislocation annihilation inside alpha globules and spheroidization of $\mathrm{Si}$ particles would significantly decrease the stress concentration during tensile testing. This would change the fracture mode from brittle to ductile as shown in Fig. 8. Fractography analysis in the current work showed that a cleavage morphology is observed for thixo-cast and ABE processed samples (Fig. 8a,b). Once the ABE-processed sample was subjected to subsequent het treatment, dimples were the main characteristic of the fracture surface (Fig. 8c). The homogeneous, dimpled matrix fracture surface contributes to more difficult crack nucleation and a delayed propagation ending in enhanced ductility. The dissolution of $\mathrm{Si}$ and $\mathrm{Mg}$ atoms and their work hardening effect could contribute to the high elongation of material after heat 
treatment. Second, the geometrical redistribution of Si particles during heat treatment may also enhance the elongation of the material. Microstructural investigations showed that during $\mathrm{ABE}$ followed by heat treatment, similar to previous works on HPT [14], FSP [24] and routes A and BA of ECAP [9], eutectic Si particles were homogenously redistributed throughout the microstructure. This enhanced the ductility as it forced the crack to pass through the primary $\mathrm{Al}$ matrix, where its propagation is much more difficult than through the initial brittle eutectic constituent. Without subsequent heat treatment, the Si particles in the eutectic region of the ABE-processed sample are not redistributed and the microstructure remains inhomogeneous. This is similar to routes $\mathrm{B}_{c}$ and $\mathrm{C}$ of ECAP [9]. This is reflected in poor ductility as the continuous eutectic constituent possesses a high density of localized and clustered pores which accelerates the nucleation of voids and their growth, and facilitates strain localization.

The difference in crack propagation is recognized by optical observation of the fracture tip of the specimens (Fig. 8d-f) As is seen in Fig. 8d and e for thixo-cast and ABE-processed samples crack path is almost normal to the tensile direction and cracks propagate along eutectic regions. For heat treated samples (Fig. 8f), however, the Si particles are not concentrated in eutectic region anymore which would make cracks to propagate intragranularly. This is similar to the fracture behavior of A356 alloy processed by different routes of ECAP. An earlier report showed that the crack path follows the eutectic constituent for routes $\mathrm{C}$ and $\mathrm{B}_{c}$, while it passes through the primary $\mathrm{Al}$ for $\mathrm{A}$ and $\mathrm{B}_{\mathrm{A}}$ routes [10]. Finally, it should be noted that employing ABE could have a significant effect on the simplification and shortening of the silicon spheroidization in A356 alloy. This would result in a significant decrease in the overall manufacturing cost of the finished component.

\section{CONCLUSION}


In the current study, the microstructure and mechanical properties of A356 aluminum alloy processed by $\mathrm{ABE}$ and subjected to silicon spheroidizing treatment were studied. The following outcomes are reported.

1- $\mathrm{ABE}$ processing at $300^{\circ} \mathrm{C}$ induced a high strain to the material resulting in an ultrafine grained A356 aluminum alloy (through continuous dynamic recrystallization) containing refined Si particles (through mechanical fragmentation). The ABE-processed material gained a high strength but, to some extent, lost its ductility.

2- High strains induced by ABE significantly accelerated the kinetics of silicon spheroidizing at $540^{\circ} \mathrm{C}$.

3- SST enhanced the elongation of the ABE processed A356 alloy at the expense of tensile strength. A compromise between strength and ductility for A356 Al alloy was achieved by coupling $\mathrm{ABE}$ and 2-min heat treatment at $540^{\circ} \mathrm{C}$.

\section{ACKNOWLEDGEMENTS}

The present work was carried out with the support of the Deakin Advanced Characterisation Facility. A part of this work was supported by the NRF Korea funded by MoE under Grant No. NRF-2016R1A6A1A03013422 (MK).

\section{References}

[1] A. Heinz, A. Haszler, C. Keidel, S. Moldenhauer, R. Benedictus, W.S. Miller, Mater. Sci. Eng. A 2000, 280, 102.

[2] O. El Sebaie, A.M. Samuel, F.H. Samuel, H.W. Doty, Mater. Sci. Eng. A 2008, 480, 342.

[3] Haghdadi, N., A. Zarei-Hanzaki, Ali A. Roostaei, A. R. Hemmati, Mater. Des. 2013, 43, 419.

[4] S. Hegde, K.N. Prabhu, J. Mater. Sci, 2008, 43, 3009.

[5] X. Jian, H. Xu, T.T. Meek, Q. Han, Mater. Lett. 2005, 59, 190.

[6] J. Wang, S. He, B. Sun, K. Li, D. Shu, Y. Zhou, Mater. Sci. Eng. A 2002, 338, 101.

[7] E. Ogris E, Development of Al-Si-Mg alloys for semi-solid processing and silicon spheroidization treatment (SST) for Al-Si cast alloys. PhD thesis, Swiss Federal Institute of Technology Zurich, Swiss; 2002. 
[8] N. Haghdadi, A. Zarei-Hanzaki, H.R. Abedi, O. Sabokpa, Mater. Sci. Eng. A 2012, 549, 93.

[9] J.M. Garcia-Infanta S. Swaminathan, A.P. Zhilyaev F. Carreno, O.A. Ruano, T.R. McNelley, Mater. Sci. Eng. A 2008, 485, 160.

[10] J.M. Garcia-Infanta, A.P. Zhilyaev, C.M. Cepeda-Jimenez, O.A. Ruano, F. Carreno, Scripta Mater. 2008, 58, 138.

[11] J.M. Garcia-Infanta, S. Swaminathan, C.M. Cepeda-Jimenez, T.R. McNelley, O.A. Ruano, F. Carreno, J. Alloys Compd. 2009 478, 139.

[12] J.M. Garcia-Infanta, A.P. Zhilyaev, F. Carreno, O.A. Ruano, J.Q. Su, S.K. Menon, T.R. McNelley, J. Mater. Sci. 2010, 45, 4613.

[13] A.P. Zhilyaev, J.M. Garcia-Infanta, F. Carreno, T.G. Langdon, O.A. Ruano, Scripta Mater. 2007, 57, 763.

[14] C.M. Cepeda-Jimenez, J.M. Garia-Infanta, A.P. Zhilyaev, O.A. Ruano, F. Carreno, Mater. Sci. Eng. A 2011, 528, 7938.

[15] T. Mungole, P. Kumar, M. Kawasaki, T.G. Langdon, J. Mater. Sci. 2015, 50, 3549.

[16] N. Haghdadi, A. Zarei-Hanzaki, S. Heshmati-Manesh, H. R. Abedi, S. B. Hassas-Irani, Mater. Des. 2013, 49, 878.

[17] E. Ogris, A. Wahlen, H. Luchinger, P. J. Uggowitzer, On the silicon spheroidization in Al-Si alloys, J. Light Metals 2002, 4, 263.

[18] R.Z. Valiev, R.K. Islamgaliev, I.V. Alexandrov, Prog. Mater. Sci. 2000, 45, 103.

[19] Y. Estrin, A. Vinogradov, Acta Mater. 2013, 61, 782.

[20] I.M. Gutierrez-Urrutia, A. Munoz-Morris, D. G. Morris, Acta Mater. 2007, 55, 1319.

[21] M. Furukawa, Y. Iwahashi, Z. Horita, M. Nemoto, T.G. Langdon, Mater. Sci. Eng. A 1998, 257, 328.

[22] T. Mungole, N. Nadammal, K. Dawra, P. Kumar, M. Kawasaki, T.G. Langdon, J. Mater.

Sci. 2013, 48, 4671.

[23] N. Haghdadi, A. Zarei-Hanzaki, H.R. Abedi, D. Abou-Ras, M. Kawasaki, A.P. Zhilyaev, Mater. Sci. Eng. A 2016, 651, 269.

[24] Z.Y. Ma, S.R. Sharma, R.S. Mishra, Scr. Mater. 2006, 54, 1623.

[25] R. Jamaati, S. Amirkhanlou, M.R. Toroghinejad, B. Niroumand, Mater. Sci. Eng. A 2011, 528, 2495.

[26] R.Z. Valiev, I.V. Alexandrov, Y.T. Zhu, T.C. Lowe, J. Mater. Res. 2002, 17, 5.

[27] S.M. Fatemi-Varzaneh, A. Zarei-Hanzaki, Mater. Sci. Eng. A 2009, 504, 104.

[28] N. Haghdadi, A. Zarei-Hanzaki, D. Abou-Ras, M. H. Maghsoudi, A. Ghorbani, M.

Kawasaki, Mater. Sci. Eng. A 2014, 595, 179.

[29] N. Haghdadi, A. Zarei-Hanzaki, D. Abou-Ras, Mater. Sci. Eng. A 2013, 584, 73.

[30] M. Moghaddam, A. Zarei-Hanzaki, M.H. Pishbin, A.H. Shafieizad, V.B. Oliveira, Mater. Charac. 2016, 119, 137.

[31] M. Kawasaki, Z. Horita, T.G. Langdon, Mater. Sci. Eng. A 2009, 524, 143.

[32] P.B. Prangnell, J.R. Bowen, P.J. Apps, Mater. Sci. Eng. A 2004, 375-377, 178.

[33] D.A. Porter, K.E. Easterling, Phase transformation in metals and alloys, Chapman and Hall, London, 1992.

[34] D. Apelian, S. Shivkumar, G. Sigworth, Trans. AFS, 1989, 97, 727.

[35] D.A. Lados, D. Apelian, L. Wang, Metall. Mater. Trans. B 2011, 42, 171.

[36] M. Haghshenas, A. Zarei-Hanzaki, M. Jahazi, Mater. Charac. 2009, 60, 817.

[37] J. Gurland, J. Plateau, Trans ASM, 1963, 56, 442. 
Table 1. Variation of elongation to fracture and strength of the A356 alloy at different conditions.

\begin{tabular}{|c|c|c|c|}
\hline & Elongation (\%) & YS (MPa) & UTS (MPa) \\
\hline Initial (Thixo-cast) & $9.1 \pm 0.2$ & $98 \pm 3$ & $199 \pm 5$ \\
\hline ABE-processed at $300^{\circ} \mathrm{C}$ & $8.0 \pm 0.6$ & $154 \pm 6$ & $385 \pm 10$ \\
\hline $\begin{array}{l}\text { ABE-processed at } 300^{\circ} \mathrm{C} \text { and } \\
\text { spheroidized at } 540 \mathrm{C} \text { for } 2 \mathrm{~min}\end{array}$ & $15.3 \pm 0.3$ & $151 \pm 4$ & $276 \pm 5$ \\
\hline $\begin{array}{l}\text { ABE-processed at } 300^{\circ} \mathrm{C} \text { and } \\
\text { spheroidized at } 540^{\circ} \mathrm{C} \text { for } 30 \mathrm{~min}\end{array}$ & $17.0 \pm 0.5$ & $115 \pm 4$ & $228 \pm 7$ \\
\hline
\end{tabular}


(a)

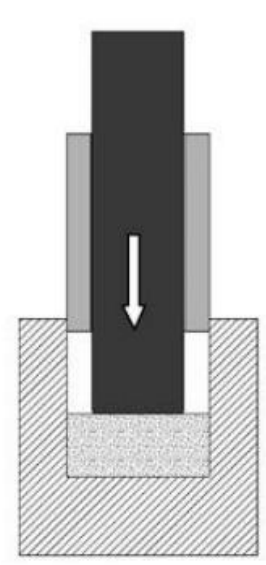

(b)

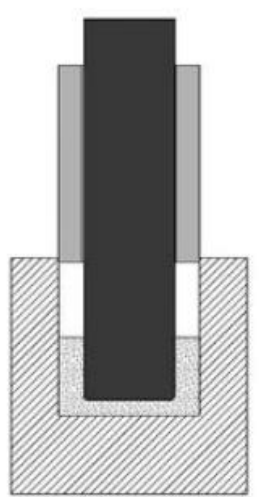

(c)

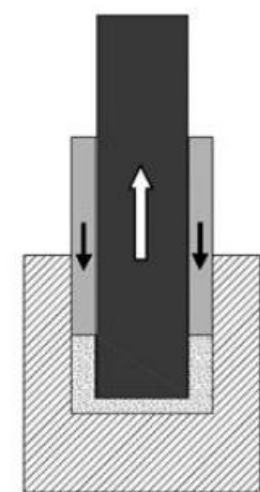

(d)

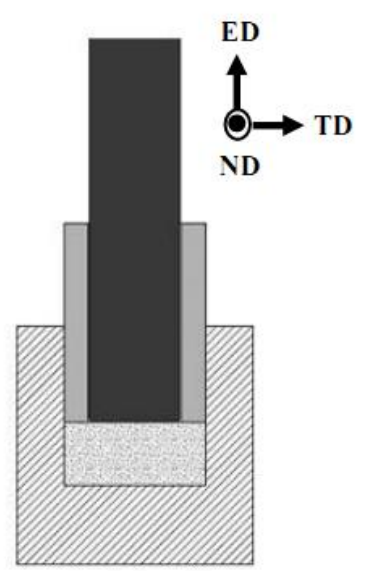

Fig.1. Schematic illustration of accumulative back extrusion processing; (a) initial state, (b) step one, back extrusion, (c) step two, back compression and (d) end of a complete pass. 

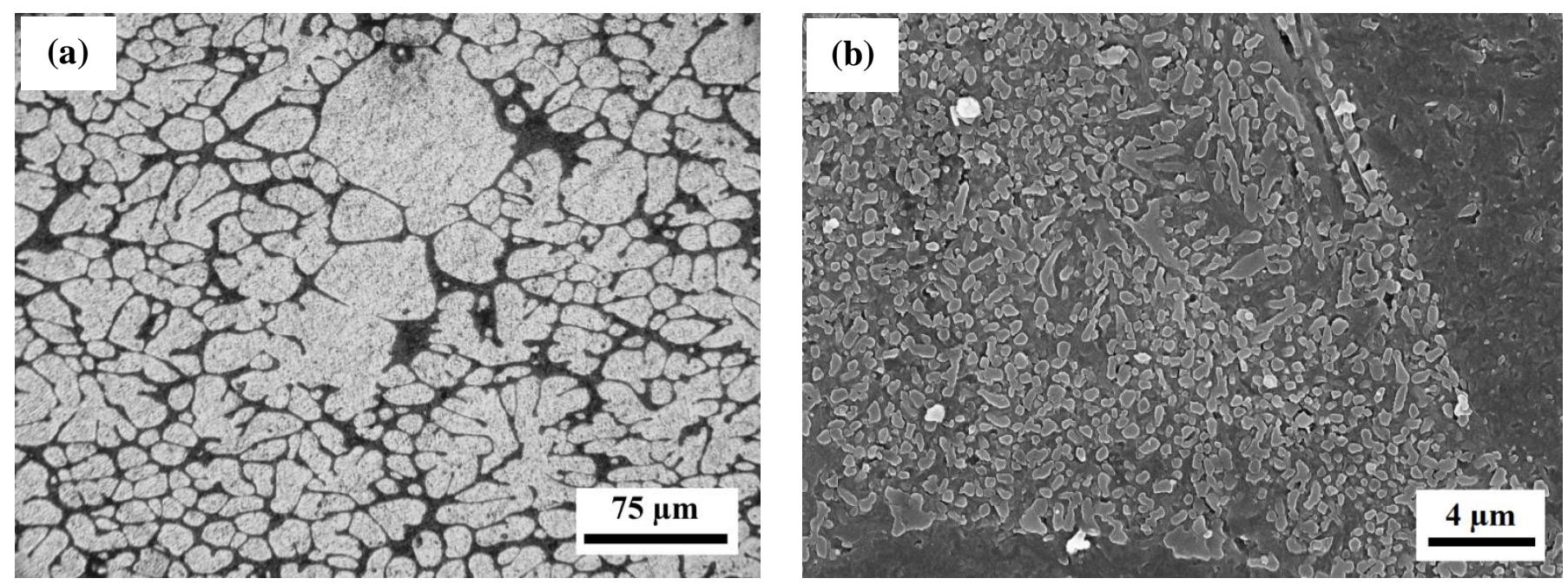

Fig. 2. Initial A356 microstructure in the thixo-cast condition; (a) low magnification optical microscopy, and (b) high resolution SEM image. 


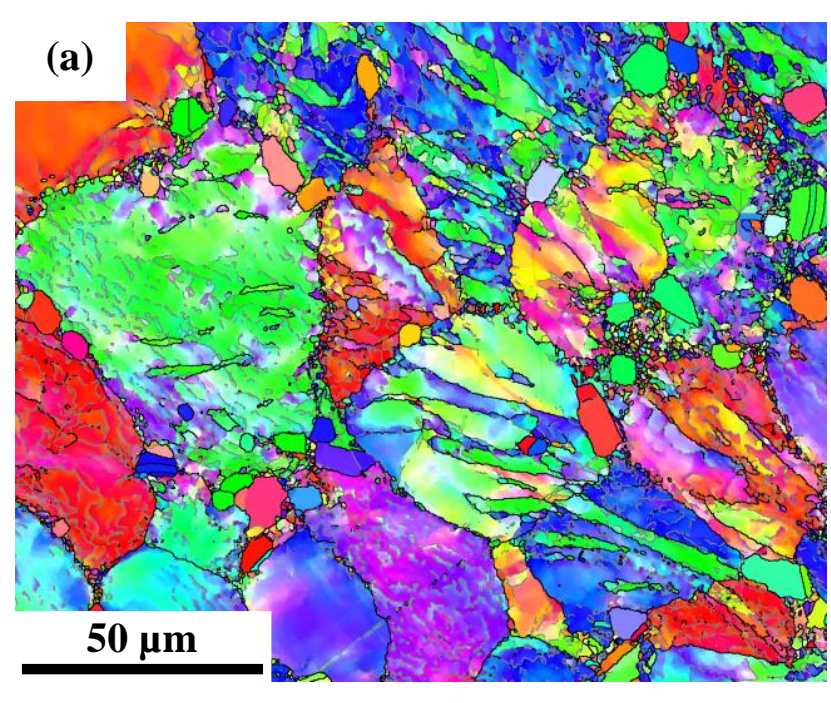

(c)

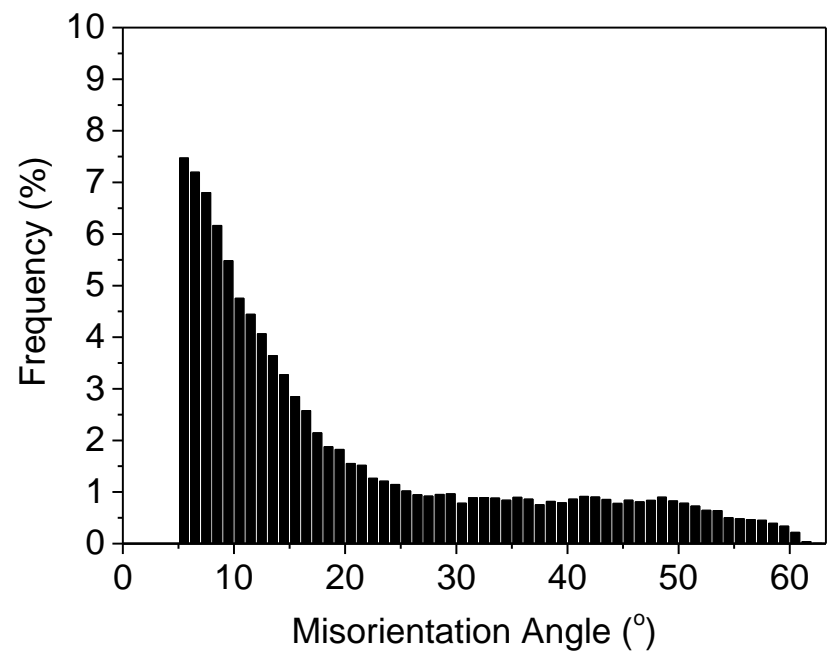

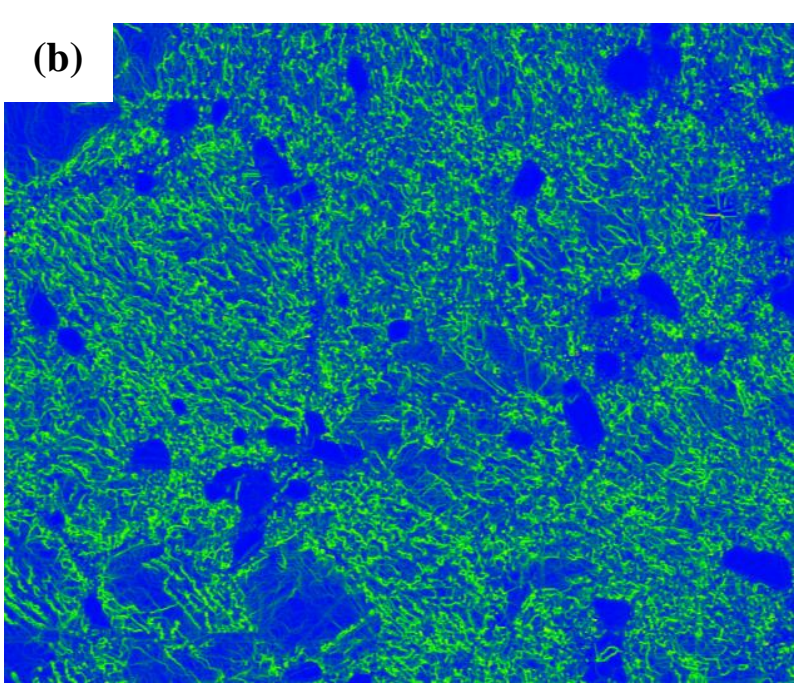

(d)

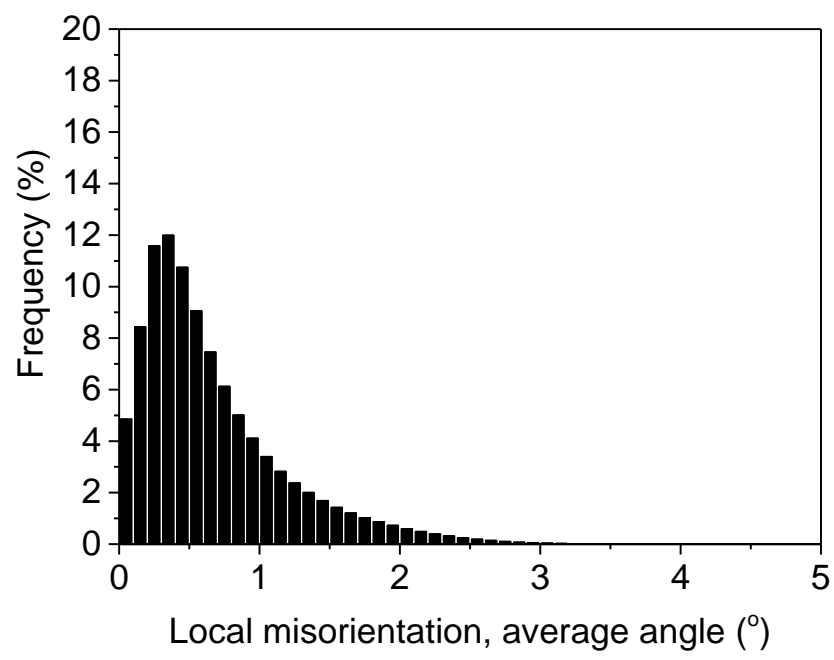

Fig 3. (a) OIM images after one complete pass of $\mathrm{ABE}$ at $300^{\circ} \mathrm{C}$ showing the complex microstructure composing low and high angle grain boundaries, (b) the corresponding kernel average misorientation (KAM) map, (c) the distribution of misorientation angle, and (d) local misorientation distribution corresponding to $(\mathrm{b})$. 


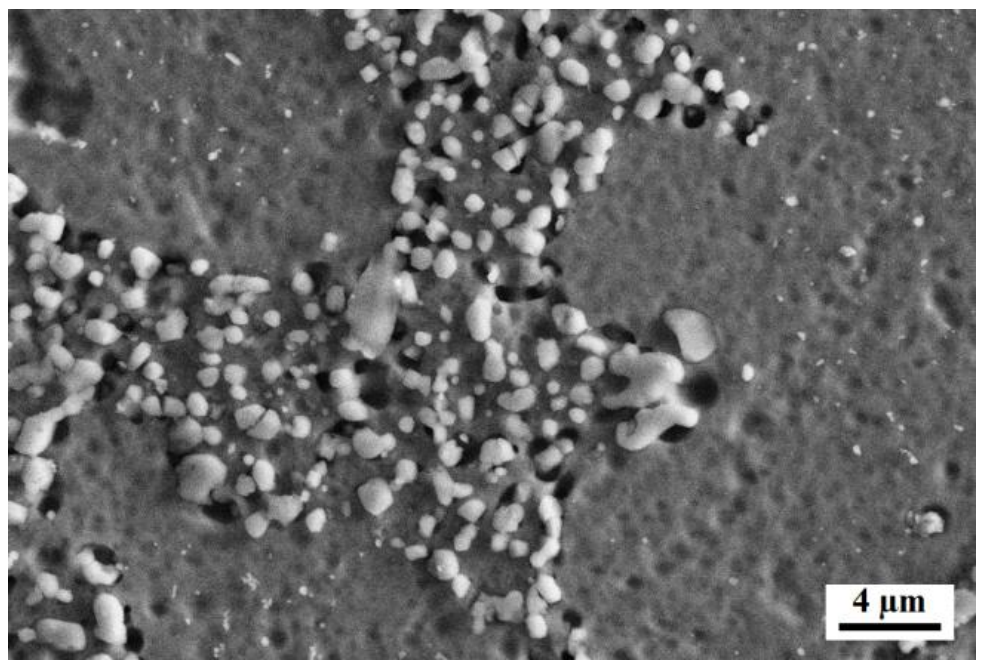

Fig 4. SEM images of A356 aluminum alloy after one complete pass of $\mathrm{ABE}$ at $300^{\circ} \mathrm{C}$ showing the complex microstructure. 

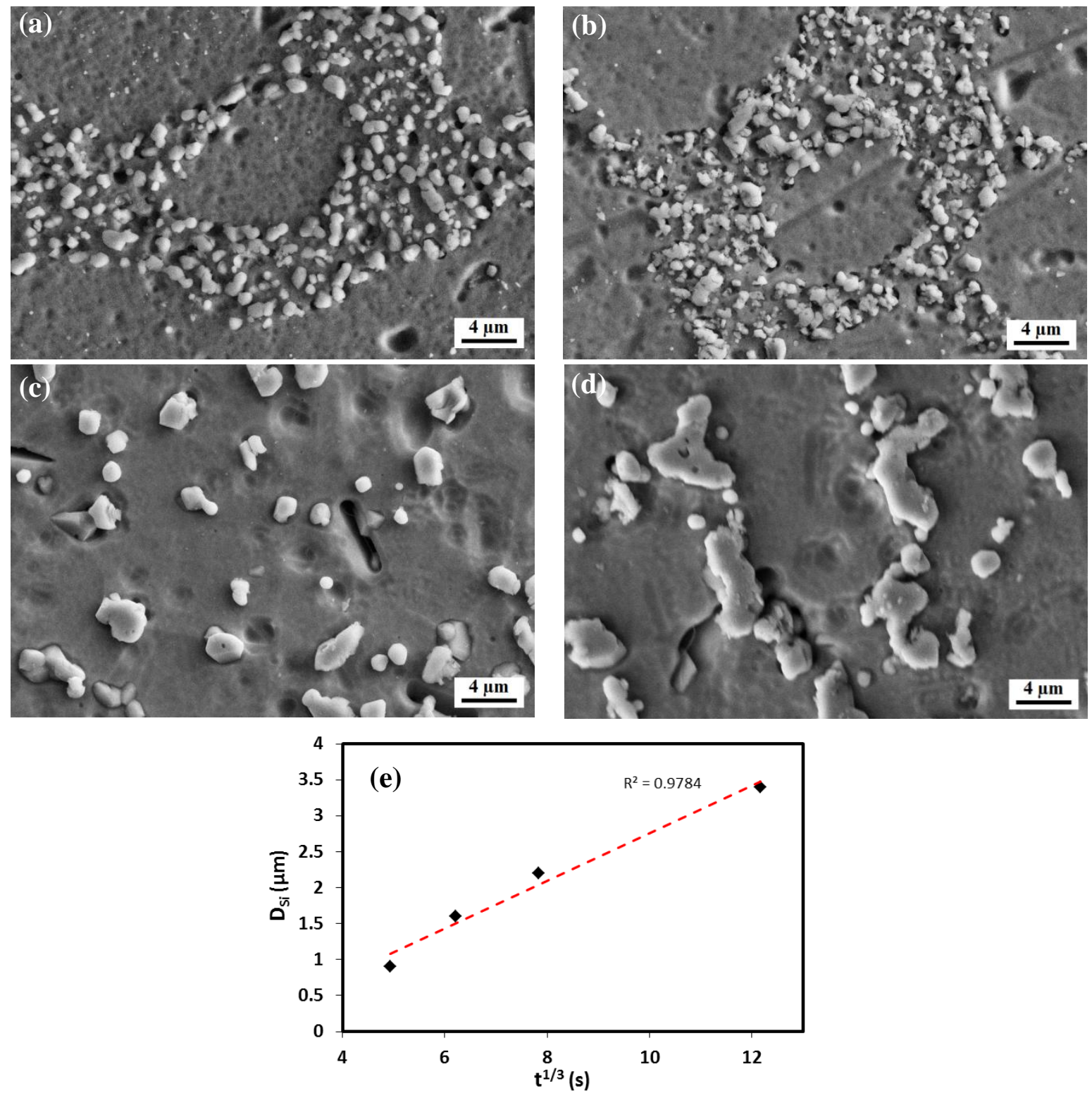

Fig 5. Variation in the size and morphology of eutectic Si particles after one complete ABE pass at $300^{\circ} \mathrm{C}$ followed by spheroidization at $540^{\circ} \mathrm{C}$ for various times; a) $2 \mathrm{~min}$ (roundness $=83 \%$ ), b) $4 \mathrm{~min}$ (roundness $=74 \%$ ), c) $8 \mathrm{~min}$ (roundness=67\%), d) $30 \mathrm{~min}$ (roundness $=59 \%$ ). (e) Plot showing average silicon diameter with time. 


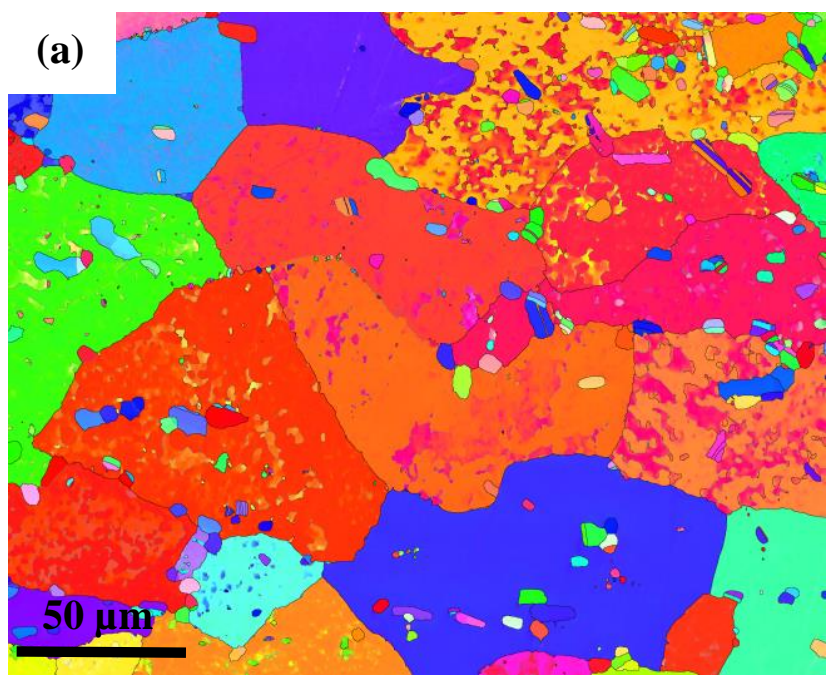

(c)

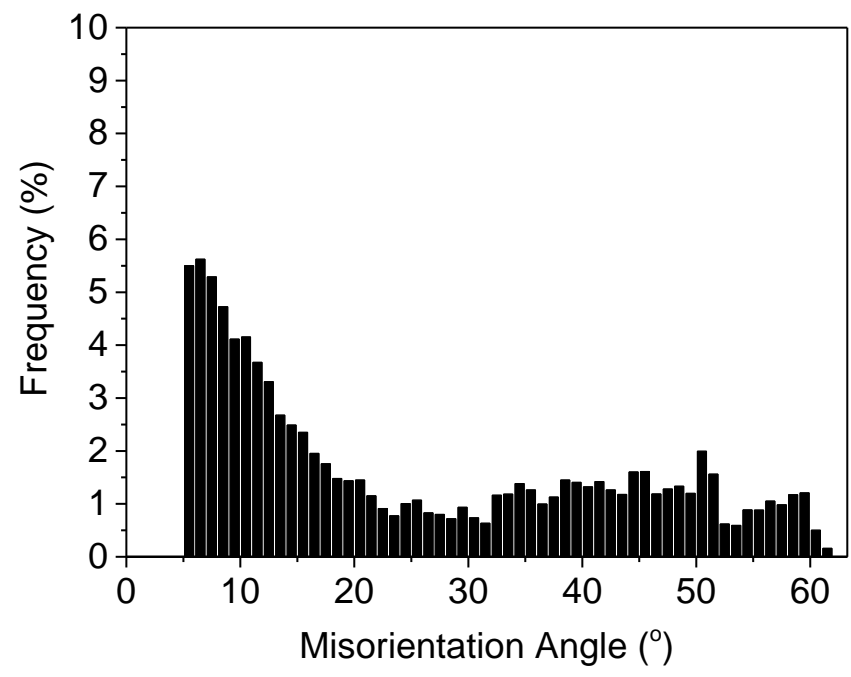

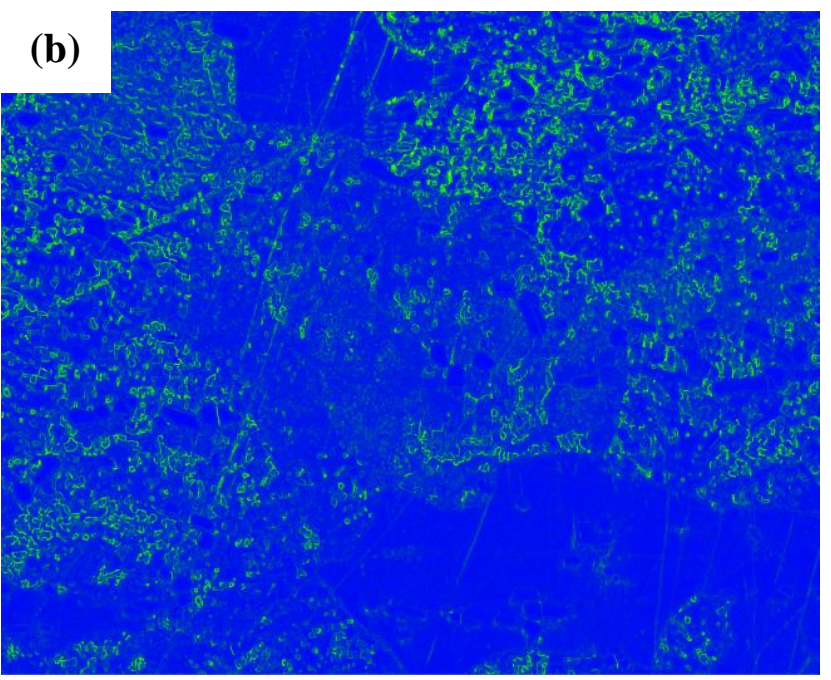

(d)

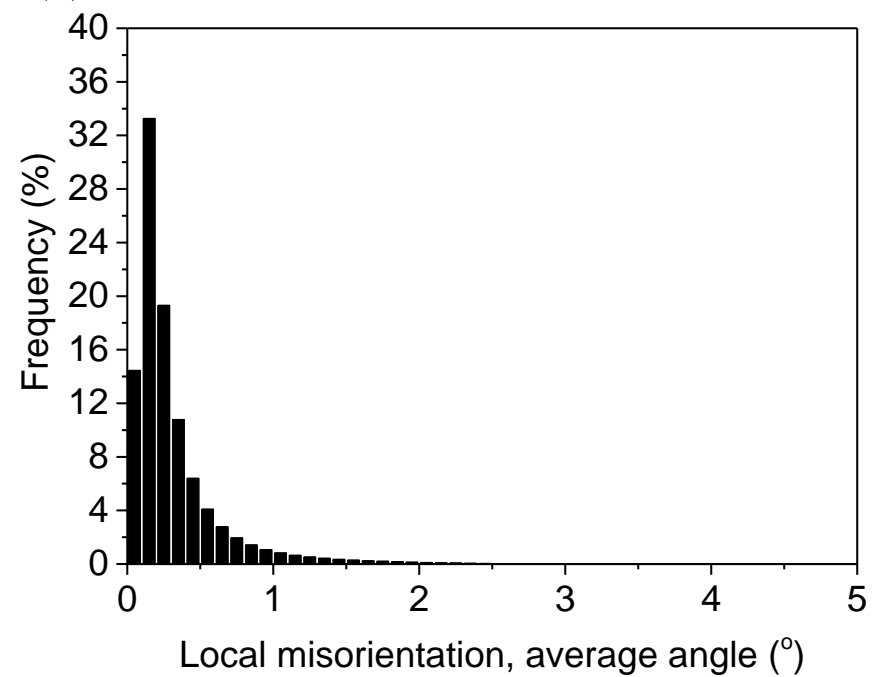

Fig 6. (a) OIM images after one complete pass of $\mathrm{ABE}$ at $300^{\circ} \mathrm{C}$ followed by 2 min spheroidizing at $540^{\circ} \mathrm{C}$, (b) the corresponding kernel average misorientation (KAM) map, (c) the distribution of misorientation angle, and (d) local misorientation distribution corresponding to (b). 


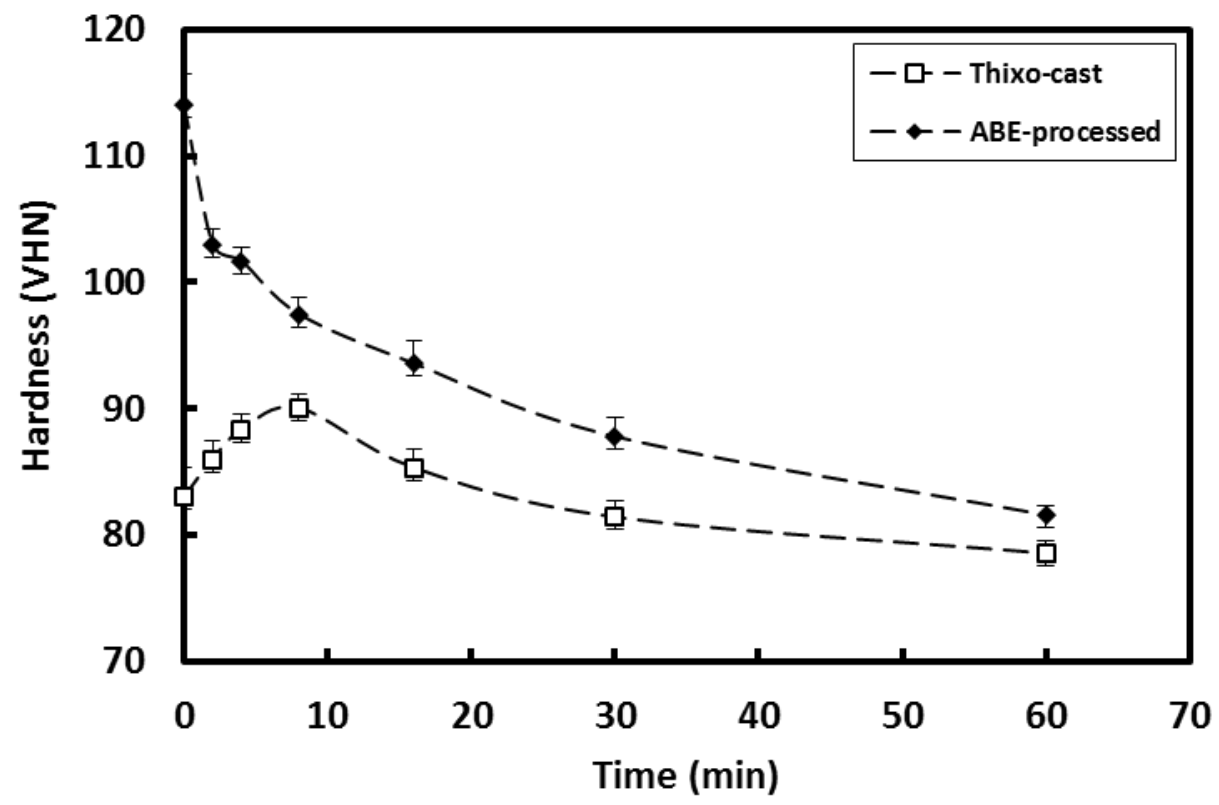

Fig 7. The variation in hardness with spheroidization time for thixo-cast and ABEprocessed $\mathrm{A} 356 \mathrm{Al}$ alloy. 

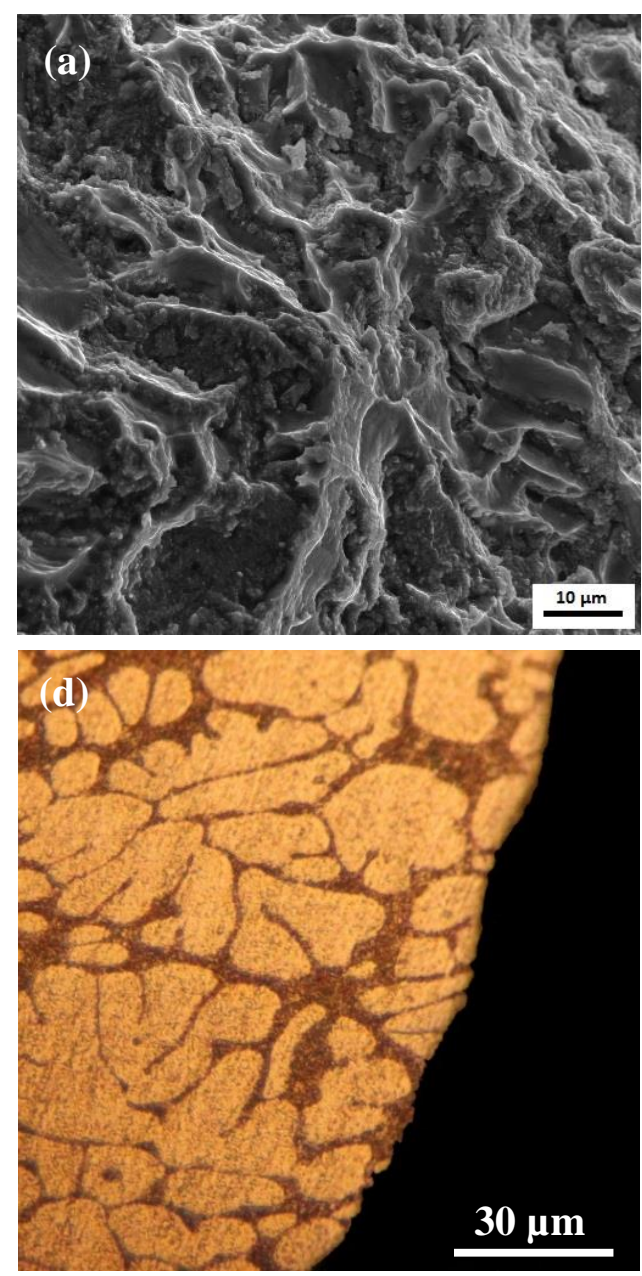

Fig. 8. The fracture surface (a-c) and cross-sectional OM image at the failure tip (d-f) of the tensile specimens

elongated to fracture for different conditions of (a,d) thixo-cast, (b,e) ABE-processed, (c,f) ABE-processed followed by heat treatment at $540{ }^{\circ} \mathrm{C}$ for $2 \mathrm{~min}$.
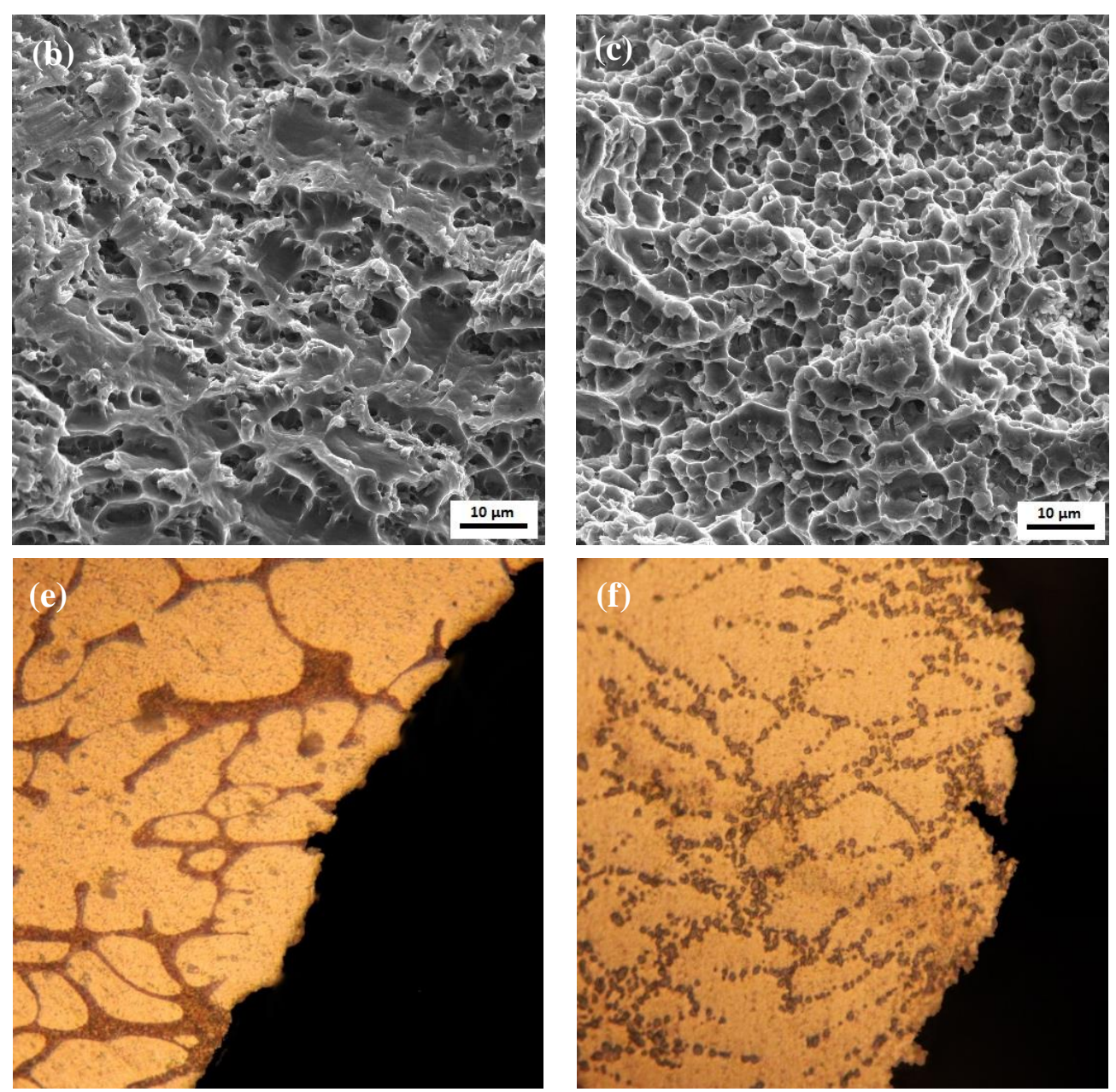